OPEN ACCESS

Edited by:

Enikö Kallay,

Medical University of Vienna, Austria

Reviewed by:

Michael F. Holick,

Boston University Medical Center

USA

Michal Zmijewski,

Medical University of Gdańsk, Poland

${ }^{*}$ Correspondence:

Daniel D. Bikle

daniel.bikle@ucsf.edu

Specialty section: This article was submitted to Integrative Physiology, a section of the journal

Frontiers in Physiology

Received: 03 March 2016 Accepted: 27 June 2016

Published: 12 July 2016

Citation:

Bikle DD, Jiang Y, Nguyen T, Oda Y and Tu C-I (2016) Disruption of Vitamin $D$ and Calcium Signaling in Keratinocytes Predisposes to Skin

Cancer. Front. Physiol. 7:296. doi: 10.3389/fphys.2016.00296

\section{Disruption of Vitamin D and Calcium Signaling in Keratinocytes Predisposes to Skin Cancer}

\author{
Daniel D. Bikle *, Yan Jiang, Thai Nguyen, Yuko Oda and Chia-ling Tu
}

Departments of Medicine and Dermatology, VA Medical Center and University of California, San Francisco, San Francisco, CA, USA

1,25 dihydroxyvitamin $\mathrm{D}\left(1,25(\mathrm{OH})_{2} \mathrm{D}\right)$, the active metabolite of vitamin $\mathrm{D}$, and calcium regulate epidermal differentiation. $1,25(\mathrm{OH})_{2} \mathrm{D}$ exerts its effects through the vitamin $\mathrm{D}$ receptor (VDR), a transcription factor in the nuclear hormone receptor family, whereas calcium acts through the calcium sensing receptor (Casr), a membrane bound member of the G protein coupled receptor family. We have developed mouse models in which the Vdr and Casr have been deleted in the epidermis ( ${ }^{\text {epid }} \mathrm{Vdr}{ }^{-/-}$and ${ }^{\text {epid }} \mathrm{Casr}^{-/-}{ }^{-}$). Both genotypes show abnormalities in calcium induced epidermal differentiation in vivo and in vitro, associated with altered hedgehog $(\mathrm{HH})$ and $\beta$-catenin signaling that when abnormally expressed lead to basal cell carcinomas (BCC) and trichofolliculomas, respectively. The $\mathrm{Vdr}^{-/-}$mice are susceptible to tumor formation following UVB or chemical carcinogen exposure. More recently we found that the keratinocytes from these mice over express long non-coding RNA (IncRNA) oncogenes such as $\mathrm{H} 19$ and under express IncRNA tumor suppressors such as lincRNA-21. Spontaneous tumors have not been observed in either the epid $V d r^{-/-}$or epid $\mathrm{Casr}^{-/-}$. But in mice with epidermal specific

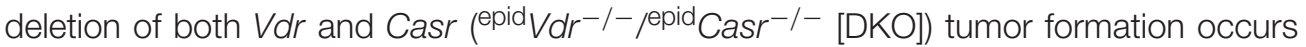
spontaneously when the DKO mice are placed on a low calcium diet. These results demonstrate important interactions between vitamin $\mathrm{D}$ and calcium signaling through their respective receptors that lead to cancer when these signals are disrupted. The roles of the $\beta$-catenin, hedgehog, and IncRNA pathways in predisposing the epidermis to tumor formation when vitamin $\mathrm{D}$ and calcium signaling are disrupted will be discussed.

Keywords: vitamin D receptor, calcium sensing receptor, squamous cell carcinoma, long non coding RNA, UVB, hedgehog, $\beta$-catenin

\section{INTRODUCTION}

Skin cancer is the most common form of cancer with an incidence estimated to be over 5 million skin cancers per year in the United States and rising (American Cancer Society, data available at http://www.cancer.org.cancer, April, 2016 update). Most of these (80\%) are basal cell carcinomas (BCC). Squamous cell carcinomas (SCC) make up another $16 \%$ and melanomas another $4 \%$. Sunlight, in particular the UVB part of the spectrum (up to 5\% of the UV light reaching earth depending on the zenith angle of the sun associated with time of day and season), is the major etiologic agent for these cancers. UVB $(280-320 \mathrm{~nm})$ is absorbed by DNA in the epidermis resulting in mutations identified as cyclobutane pyrimidine dimers (CPDs) and pyrimidine (6-4) pyrimidone photoproducts (6-4 PP) that lead to $\mathrm{C}$ to $\mathrm{T}$ or CC to TT mutations if not repaired. These are commonly referred to as the UVB "signature" lesion (Freeman et al., 1989; Hussein, 2005). On the other hand UVA (320-400 nm), comprising $95 \%$ of the UV light reaching earth, 
is capable of penetrating into the dermis and does its DNA damage primarily by oxidative processes (e.g., 8 hydroxy $2^{\prime}$ deoxyguanosine production), but CPDs may be produced at higher levels (Besaratinia et al., 2005). On the other hand UVB is required for vitamin $\mathrm{D}_{3}$ production converting 7dehydrocholesterol levels in the skin to pre vitamin $\mathrm{D}_{3}$, which then isomerizes to vitamin $\mathrm{D}_{3}$. White males with class III pigmentation require $18 \mathrm{~mJ} / \mathrm{cm}^{2}$ UVB exposure for vitamin $\mathrm{D}_{3}$ production, (Matsuoka et al., 1989), a dose not likely to lead to tumors in most individuals. However, the efficiency of vitamin $\mathrm{D}$ production by solar radiation is less than that of monochromatic UVB in part due to the UVA portion of solar radiation that influences the ratio of pre $\mathrm{D}_{3}$ to lumisterol ${ }_{3}$ produced and that may contribute to tumor formation over and above that of UVB (MacLaughlin et al., 1982; Agar et al., 2004). Vitamin $D_{3}$ production is not the only metabolic step of which the skin is capable. Both the further conversion to $25 \mathrm{OHD}_{3}$ (via Cyp27A1 and Cyp2R1) and then to its active metabolite $1,25(\mathrm{OH})_{2} \mathrm{D}_{3}$ (via Cyp27b1) (Bikle et al., 1986) take place. This latter step is promoted by UVR (Muthusamy and Piva, 2009), perhaps by stimulation of the expression of cytokines such as TNF (Bikle et al., 1991). Moreover the vitamin D receptor (VDR) is expressed in both melanocytes (Colston et al., 1982) and keratinocytes (Pillai et al., 1988) and have been shown to respond to $1,25(\mathrm{OH})_{2} \mathrm{D}_{3}$ by a reduction in proliferation and promotion of differentiation (Colston et al., 1981; Bikle, 2012b). A key rationale for our studies in the protective role of calcium and vitamin $\mathrm{D}$ signaling in UVR induced skin cancer is that the $1,25(\mathrm{OH})_{2} \mathrm{D}_{3}$ produced in the skin under the influence of UVR provides protection against UVB and likely UVA induced tumors, a rationale supported by epidemiologic evidence that suggests benefit of low dose UVR. For example, modest increases in UVB appeared to be protective against skin cancer in a meta analysis of 10 US studies (Armstrong and Kricker, 2001), although higher doses of UVB were not protective. Moreover, no significant correlation in SCC incidence was observed in association with time spent outdoors in an Australian population study (English et al., 1998). In a multicenter European study Rosso et al. (1996) identified a threshold of 70,000 accumulated hours of sunshine below which an increase in SCC was not observed, although the threshold for BCC was lower. Thus, the clinical evidence is at least supportive if not definitive for a protective role of low dose UVB, mediated we submit via vitamin $\mathrm{D}$ production. Although a similar case has not been made for calcium in epidermal tumor formation, the epidemiologic data demonstrating protection against colorectal cancer by diets high in calcium and vitamin D is substantial (Garland et al., 1985; Chakrabarty et al., 2005), and as will be discussed later in this article, the role of calcium appears to be synergistic with that of vitamin D.

\section{REGULATION OF KERATINOCYTE PROLIFERATION AND DIFFERENTIATION BY CALCIUM AND 1,25(OH $)_{2}$ D}

Calcium and $1,25(\mathrm{OH})_{2} \mathrm{D}$ are critical for keratinocyte differentiation. Calcium concentrations below $0.07 \mathrm{mM}$ promote proliferation, whereas increasing the extracellular calcium concentration (Cao) above $0.1 \mathrm{mM}$ (calcium switch) induces differentiation. Among the changes are the translocation of proteins such as E-cadherin to the membrane to form the E-cadherin/catenin complex (adherens junctions). Proteins associated with this complex include phosphatidyl inositol 3 kinase $(\mathrm{PI} 3 \mathrm{~K})$, various catenins including $\beta$-catenin, and phosphatidyl inositol 4-phosphate 5-kinase $1 \alpha$ (PIP5K1A). These proteins in this complex mediate much of the ability of calcium and vitamin D to promote differentiation (Tu et al., 2001, 2005; Xie et al., 2005, 2009; Xie and Bikle, 2007; Tu C. et al., 2008). Other important proteins whose translocation to the membrane promotes the differentiation process include the calcium sensing receptor (Casr), phospholipase C- $\gamma 1$ (Plcg1), and the Src family of tyrosine kinases, the activation of which phosphorylate the catenins facilitating their binding to E-cadherin to form the E-cadherin/catenin complex. These changes then lead to the sequential induction of proteins including keratins Krtl and Krt10 (Yuspa et al., 1989), profilaggrin (the precursor of filaggrin [Flg]), involucrin (Ivl), and loricrin (Lor). These and other proteins are cross linked into the insoluble cornified envelope by the calcium induced transglutaminase 1 (Tgm1) (Thacher and Rice, 1985; Hohl, 1990), the final step in the differentiation process.

The Casr underlies the ability of the keratinocyte to respond to calcium (Tu et al., 2004, 2011, 2012; Tu C. et al., 2008). The Casr through the scaffold protein filamin activates the RhoA pathway that in turn activates the src kinase family, which phosphorylate the catenins, facilitating their binding to E-cadherin ( $\mathrm{Tu}$ et al., 2011). We cloned the Casr from keratinocytes (Oda et al., 1998) and subsequently developed a mouse expressing a floxed form of Casr (exon 7 encoding the entire transmembrane domain and intracellular portion of the gene; Chang et al., 2008; Tu C. et al., 2008). This enables us to delete the gene in the tissue of our choice, in this case the keratinocyte where we demonstrated the central role of Casr in calcium signaling within the keratinocyte and its impact on differentiation (Tu C. et al., 2008; Tu et al., 2012). Mice lacking the Casr develop a defective permeability barrier due to abnormal production of essential lipids and proteins required for barrier formation as well as a defective innate immune response. Similar abnormalities develop in mice with $V D R$ or $C y p 27 b 1$ gene deletions. Moreover, deletion of Casr also results in reduced expression of $V d r$ and Cyp27b1 (Tu et al., 2012), likely contributing to the failure of the epidermis of Casr deficient mice to differentiate normally. On the other hand $1,25(\mathrm{OH})_{2} \mathrm{D}$ induces the Casr (Canaff and Hendy, 2002). Just as $1,25(\mathrm{OH})_{2} \mathrm{D} / \mathrm{VDR}$ induces Casr, calcium/Casr is required for $\mathrm{Vdr}$ and Cyp27b1 expression, demonstrating the strong interaction between calcium and vitamin $\mathrm{D}$ signaling in the skin with respect to differentiation. Thus, the actions of $1,25(\mathrm{OH})_{2} \mathrm{D} / \mathrm{VDR}$ enhance the keratinocyte response to the prodifferentiating actions of calcium (Ratnam et al., 1999), whereas the effect of Casr in the expression of $V d r$ and Cyp27b1 (Tu et al., 2012) enhances the prodifferentiating actions of $1,25(\mathrm{OH})_{2} \mathrm{D}$ ( $\mathrm{Su}$ et al., 1994). With respect to cancer, this synergistic interaction is an important concept to which we will return.

The synergism between Casr and VDR is well-demonstrated by the joint regulation of the expression of a number of 
genes by calcium and $1,25(\mathrm{OH})_{2} \mathrm{D}$ including the phospholipase C (Plc) family members (Xie and Bikle, 1997) important for differentiation, the processing of the lipids required for permeability barrier formation (Oda et al., 2009), and the enhancement of the innate immune response via induction of toll like receptor 2 (TLR2) and its coreceptor CD14, that initiate the innate immune response in skin leading to the expression of defensins such as cathelicidin (Schauber et al., 2007). Moreover, both calcium and $1,25(\mathrm{OH})_{2} \mathrm{D}$ inhibit genes such as Myc (Matsumoto et al., 1990) and Ccnd1 (Bikle, 2011) while inducing cell cycle inhibitors Cdnk1a (aka p21 cip) and Cdnk1b (aka p27 kip), which contribute to the antiproliferative actions of calcium and $1,25(\mathrm{OH})_{2} \mathrm{D}$. The roles of calcium/Casr and $1,25(\mathrm{OH})_{2} \mathrm{D} / \mathrm{VDR}$ in immune regulation as well as in proliferation and differentiation likely contribute to their roles in protection of the skin against the development of skin cancer.

\section{THE ROLES OF VDR AND Casr IN CANCER PROTECTION}

Zinser et al. (2002) made the first clear demonstration of the predisposition to tumor formation in the skin of mice lacking VDR. They administered the carcinogen 7, 12 dimethylbenzanthracene (DMBA) to $V d r$ null mice and wildtype mice and found that nearly all the $V d r$ null mice developed papillomas, whereas few if any of the wildtype mice did. Others have confirmed these results (Indra et al., 2007). Moreover, Vdr null mice have also been shown to be predisposed to tumor formation following prolonged UVB exposure first by Ellison et al. (2008) and subsequently by our own group (Teichert A. E. et al., 2011). Following UVB both SCC and BCC develop, not just papillomas. Part of this predisposition to tumor formation is due to a defective DNA damage repair process (review in Bikle, 2012a). The appearance of BCC suggested that the hedgehog $(\mathrm{HH})$ signaling pathway was involved, as mutations in this pathway underlie essentially all BCC (Aszterbaum et al., 1998). However, skin lacking VDR also results in BCC when $\beta$-catenin signaling is increased (Pálmer et al., 2008). Thus, we became interested in the interacting roles of $\mathrm{HH}$ and $\beta$-catenin signaling in tumor suppression by VDR, a subject to which I will return.

When we knocked out both $V d r$ and Casr in keratinocytes ( ${ }^{\text {epid }} V d r^{-/-} /$epid $\mathrm{Casr}^{-/-}, \quad$ DKO), tumors developed spontaneously, something that we had not observed in mice in which either gene was deleted by itself (Bikle et al., 2015). In this case the tumors were SCC. Colorectal cancer provides a good model for the development of skin tumors in that abnormalities in calcium, vitamin $D$ and $\beta$-catenin signaling have also been implicated in the development of colorectal cancer with human colorectal cancer cell lines (Chakrabarty et al., 2003, 2005; Bhagavathula et al., 2007; Liu et al., 2010; Wang et al., 2010). A frequently used model involves a mutated $A p c$ resulting in increased Wnt/ $\beta$-catenin signaling (Arimura et al., 2009). Activation of the $\mathrm{Wnt} / \beta$-catenin pathway increases proliferation and reduces apoptosis, whereas inhibition of this pathway has the reverse effect (Varnat et al., 2009). As it does in keratinocytes calcium via the Casr blocks the translocation of $\beta$-catenin to the nucleus in part by increasing its binding to the E-cadherin/catenin complex in the membrane, thus blocking its transcriptional activity (Chakrabarty et al., 2003). Like the situation in keratinocytes, $1,25(\mathrm{OH})_{2} \mathrm{D}$ synergizes with calcium in these actions by inducing the expression of Casr (Chakrabarty et al., 2005), increasing the expression of the cell cycle inhibitors Cdkn1a and Cdkn1b, and inhibiting the expression of Myc, Ccnd1, survivin (Birc5), and thymidylate synthase (Tyms; Bhagavathula et al., 2007; Liu et al., 2010). In addition to its stimulation of E-cadherin/catenin complex formation, thus limiting the access of $\beta$-catenin to the nucleus, $1,25(\mathrm{OH})_{2} \mathrm{D}$ induces an inhibitor of Wnt $/ / \beta$-catenin signaling, dickkopf 1 (Dkk1; Pendas-Franco et al., 2008). Our studies in which Casr was deleted from the intestinal epithelial cell (Rey et al., 2011) demonstrated hyperproliferation in these cells. This was accompanied by increased localization of $\beta$-catenin in the nuclei signifying activation of $\beta$-catenin signaling. Again comparable to that shown in the skin, mice lacking $V d r$ in the intestinal epithelium were predisposed to carcinogen induced tumor formation (Byers et al., 2011). Whether deleting both $V d r$ and Casr will lead to spontaneous colorectal tumors remains to be tested.

$1,25(\mathrm{OH})_{2} \mathrm{D}$ has also been shown to be protective against UVA induced oxidative induced mutations in DNA (GordonThomson et al., 2012). UVA induces reactive oxygen species (ROS) such as superoxide anion $\left(\mathrm{O}_{2}^{-}\right)$, hydrogen peroxide, and hydroxyl radicals as well as nitric oxide $(\mathrm{NO})$ via stimulation of NO synthase. NO combines with $\mathrm{O}_{2}^{-}$to form peroxynitrite that causes oxidative and nitrative modifications of DNA bases such as 8 oxo 2 deoxyguanosine (D'Orazio et al., 2013). These UVA fingerprint lesions along with UVB fingerprint lesions have been found in human SCC (Agar et al., 2004). Of interest is that the protection by $1,25(\mathrm{OH})_{2} \mathrm{D}$ of the formation of these UVA fingerprint mutations may not require the VDR (GordonThomson et al., 2012), and the role of calcium in their formation has not been studied.

\section{THE HEDGEHOG (HH) PATHWAY IN EPIDERMAL TUMOR FORMATION}

Activation of HH signaling has been shown to result in BCC in both animals and humans (Hahn et al., 1996), and appears also to predispose to UVB induced SCC (Ping et al., 2001). This was first demonstrated when PTCH1 mutations were found to be the cause of the basal cell nevus syndrome (BCNS) (Gorlin Syndrome), a syndrome in which patients readily develop BCCs (Hahn et al., 1996; Aszterbaum et al., 1998). This syndrome has been reproduced in a mouse model with Ptch1 mutations (Aszterbaum et al., 1999). Subsequently it was found that essentially all BCCs, sporadic or part of the BCNS, have mutations in PTCH1 or other elements of the HH signaling pathway (Aszterbaum et al., 1998), and nearly all BCC in humans or mice overexpress Ptch1 or one of the other components of the HH pathway (Tojo et al., 1999; Bonifas et al., 2001). A drug, vismodegib, targeting the HH pathway, has recently been developed as the first effective non-surgical 
treatment for advanced BCC (Sekulic et al., 2012; Tang et al., 2012).

In the basal state Ptch1 inhibits the function of smoothened (Smo), like Ptch1 a membrane protein. Smo, in the inhibited state, keeps the Gli family of transcription factors bound to suppressor of fused (Sufu) within the cytoplasm, thus limiting their translocation to the nucleus (Barnfield et al., 2005; Svärd et al., 2006). Sonic hedgehog (Shh) binding to Ptch1 reverses its inhibition of Smo enabling the release of the Gli factors from Sufu and their entry into the nucleus. Gli1 and 2 are the main actors in gene transcription (Mimeault and Batra, 2010). Their transcriptional activity includes the increased expression of other components of the $\mathrm{HH}$ pathway, as well as anti apoptotic and cell cycle factors including Bcl2, Ccnd1,2, E2f1, Cdc45, thus promoting proliferation, while suppressing genes associated with keratinocyte differentiation including the VDR (Grachtchouk et al., 2000; Nilsson et al., 2000; Regl et al., 2002, 2004a,b). When Gli1, Gli2, or Shh are overexpressed in basal keratinocytes, BCC develop (Oro et al., 1997; Grachtchouk et al., 2000; Nilsson et al., 2000). Similarly human keratinocytes overexpressing Shh develop BCC like lesions when grafted unto nude mice (Fan et al., 1997).

$V d r$ null animals overexpress elements of the $\mathrm{HH}$ signaling pathway in their epidermis (Teichert A. et al., 2011), although they show reduced expression in the cycling portion of their hair follicles (Teichert et al., 2010). Consensus sequences for vitamin D response elements (VDRE) in the promoters of Shh, Ptch1, Ptch2, Gli1, and Gli2 have been identified (Reddy et al., 2004; Wang et al., 2005; Pálmer et al., 2008; Luderer et al., 2011), and we (Teichert A. et al., 2011) have demonstrated that $1,25(\mathrm{OH})_{2} \mathrm{D}$ inhibits their expression in a VDR dependent fashion. Moreover, vitamin D per-se has been shown to suppress Smo (Bijlsma et al., 2006; Tang et al., 2011), presumably by a nongenomic mechanism. These findings in the epidermis stand in stark contrast to the role of VDR during HF cycling where the unliganded VDR appears to promote the ability of $\mathrm{HH}$ signaling to initiate early anagen (Lisse et al., 2014).

\section{$\beta$-CATENIN SIGNALING IN EPIDERMAL TUMOR FORMATION}

Benign hair follicle tumors, pilomatricomas or trichofolliculomas, result from over activation of the wnt $/ \beta$ catenin pathway (Gat et al., 1998; Chan et al., 1999; Xia et al., 2006). However, this depended on the VDR status of the animal. Pálmer et al. (2008) demonstrated an interaction between VDR and $\beta$-catenin in transcriptional regulation. They found putative response elements for VDR and $\beta$-catenin /LEF1 in a number of genes including those of the $\mathrm{HH}$ signaling pathway. Moreover, an analog of $1,25(\mathrm{OH})_{2} \mathrm{D}$ could block the formation of these hair follicle tumors induced by overactivation of the wnt/ $\beta$-catenin pathway. On the other hand, mice lacking VDR developed BCC rather than the more benign trichofolliculomas when the wnt/ $\beta$-catenin pathway was overactivated. In humans trichofolliculomas were found to have high nuclear levels of both $\beta$-catenin and VDR, whereas BCC have high levels of $\beta$-catenin but low levels of VDR (Pálmer et al., 2008). These data indicate the importance of the interactions between VDR and $\beta$-catenin in the hair follicle and in the epidermis in both mice and humans. As in $\mathrm{HH}$ signaling, these interactions are complex in that VDR is required for $\beta$-catenin activation in the hair follicle (Lisse et al., 2014), such that when $\beta$-catenin transcriptional activity is prevented as in the VDRKO, hair follicle formation is blocked (Huelsken et al., 2001). On the other hand suppression of $\beta$-catenin transcriptional activity by VDR in the epidermis appears to be protective with respect to tumor formation (Wei et al., 2007).

As noted earlier both the Casr and VDR are required for the formation of the E-cadherin/catenin complex, which is not only required for the differentiation of the keratinocyte, but by keeping $\beta$-catenin bound to the membrane prevents its nuclear translocation and activation of genes promoting proliferation. Loss of the E-cadherin/catenin complex is a well-known marker of malignant transformation in a number of epithelial cells (Ghahhari and Babashah, 2015). Moreover, we (Tu et al., 2007; Tu C.L. et al., 2008) have shown that deletion of the Casr from keratinocytes reduces their stores of calcium and blocks their response to extracellular calcium (Cao) including the formation of the E-cadherin/catenin complex.

The $\beta$-catenin and HH pathways interact (Bienz, 2005; Pálmer et al., 2008). Using a constitutively active Smo $\left[G t(R O S A) 26 \operatorname{Sor}^{t m 1}\left(S_{m o} / E Y F P\right) A m c\right]$ in keratinocytes to induce BCC, two groups (Yang et al., 2008; Youssef et al., 2012) found a rapid increase in genes of the Wnt/ $\beta$-catenin pathway. $D k k 1$ overexpression or deletion of Ctnnb1 prevented the development of BCC. Both $\mathrm{HH}$ and Wnt/ $\beta$-catenin pathway constituents were found to be over expressed in a series of human BCC (Youssef et al., 2012). Putative $\beta$-catenin /LEF1 response elements as well as VDRE mentioned earlier have been found in a number of HH pathway genes (Pálmer et al., 2008), which unlike the VDRE appear to be stimulated by activated $\beta$-catenin with an increase in Shh expression (Schneider et al., 2010). The role of VDR in the regulation of these two pathways is shown in Figure 1.

\section{LONG NON-CODING RNAS (LncRNA)}

Approximately 20,000 protein-coding genes are encoded by the human genome. This represents less than $2 \%$ of the total genomic sequence. That said $90 \%$ of the genome is actively transcribed without protein coding potential (Mercer et al., 2009). These non-coding transcripts are arbitrarily divided into short and long non-coding RNAs with small non-coding RNAs defined as less than 200 bases, including tRNAs, microRNAs, and small nuclear (snoRNAs), and long non-coding RNAs (lncRNAs) as those with lengths larger than 200 bases, some over $100 \mathrm{~kb}$ in length (Gibb et al., 2011). Much of the transcriptome is comprised of lncRNAs ( $\sim 80 \%$; Mercer et al., 2009), and over 23,000 have been identified so far. Like mRNAs they are spliced and contain polyadenylation signals, (Mattick, 2011). Many regulatory processes are controlled by lncRNAs including embryonic pluripotency, differentiation, and body axis patterning, promoting developmental transitions (Mattick, 2011; Batista and Chang, 2013). LncRNAs can influence the epigenetic programs of the transcriptome through their regulation of histone modifications (Spitale et al., 2013). Of particular relevance to this review is that lncRNAs 


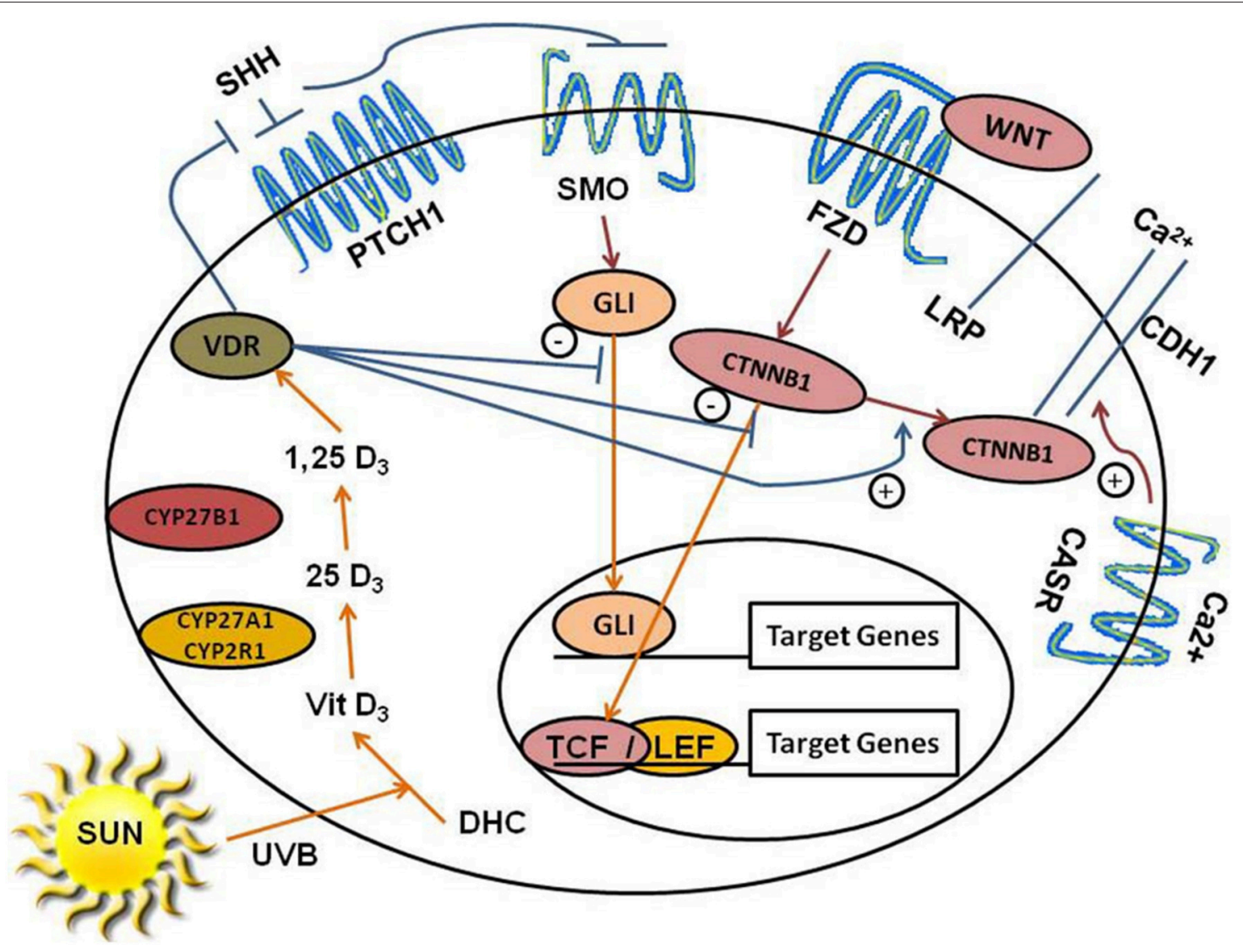

FIGURE $\mathbf{1}$ | Regulation of $\mathbf{H H}$ and $\mathbf{W n t} / \boldsymbol{\beta}$-catenin signaling by $\mathbf{1 , 2 5}(\mathbf{O H})_{\mathbf{2}} \mathbf{D} / \mathbf{V D R}$ and calcium/Casr. The keratinocyte expresses VDR and is capable of making its own 1,25(OH) ${ }_{2} \mathrm{D}_{3}$ from the vitamin $\mathrm{D}_{3}$ produced from 7-dehydrocholesterol (DHC) under the influence of UVB, as it has both Cyp27a1/Cyp2r1 (which convert vitamin $\mathrm{D}_{3}$ to $25 \mathrm{OHD}_{3}$ ) and Cyp27b1 [which converts $250 \mathrm{HD}_{3}$ to $1,25(\mathrm{OH})_{2} \mathrm{D}_{3}$ ]. The keratinocyte also expresses the calcium sensing receptor Casr required for calcium induced differentiation. 1,25(OH) 2 D/NDR suppresses Shh and Gli1 expression, inhibiting the HH pathway in keratinocytes. 1,25(OH) 2 D/VDR binds CTNNB1 ( $\beta$-catenin) and increases CDH1(E-cadherin) levels in the plasma membrane reducing the amount of $\beta$-catenin available for binding to TCF/LEF in the nucleus limiting its transcriptional activity. Calcium acting through its receptor is required for the formation of the E-cadherin/catenin complex in the plasma membrane. In combination these actions reduce the proliferative actions of Shh and Wnt/ $\beta$-catenin signaling in keratinocytes, limiting their ability to induce tumors in the skin.

regulate cancer development through a number of effects on tumor cell proliferation, blocking growth suppressors, inducing angiogenesis, and promoting invasion and metastasis (Gibb et al., 2011; Gutschner and Diederichs, 2012; Li et al., 2013).

We (Jiang and Bikle, 2014) evaluated the potential role of lncRNAs in VDR protection against skin tumor formation using in vitro cultured mouse keratinocytes and an in vivo mouse model, comparing cell or mouse epidermis from wildtype or $V d r$ null animals, in an array containing 90 well-annotated mouse lncRNAs. We found increased expression of several well-known oncogenes, including H19, HOTTIP, and Nespas, and reduced expression of tumor suppressor genes such as Kcnq1ot1, lincRNA-p21 in VDR deleted keratinocytes whether from cultured cells or epidermis. These results point to an additional mechanism for protection by VDR against skin cancer formation that we are in the early stages of exploring. Whether concomitant Casr deletion will amplify these results has not yet been determined.

\section{CONCLUSIONS}

Both calcium and vitamin $\mathrm{D}$ signaling through their respective receptors Casr and VDR are important for the normal functions of the skin. In this article we have focused on their roles in tumor development when such signaling is disrupted by deletion of the receptors. At this point we have not observed tumor formation in the skin of mice lacking only the Casr, but have observed that mice lacking both Casr and VDR develop tumors of greater malignancy and spontaneity than seen in mice lacking only the VDR. Analyses of gene expression in the epidermis from mice lacking one or both of these receptors clearly demonstrate the synergism between VDR and Casr in gene regulation including genes involved with cancer such as the E-cadherin/catenin pathway that plays such an important role in the epithelial/mesenchymal transition leading to tumor formation. We have focused on two pathways, $\mathrm{HH}$ and Wnt/ $\beta$-catenin, that are regulated by VDR and Casr, and that are plausible participants in epidermal tumor formation when 
their regulation is disrupted. In addition we have introduced a new mechanism, alterations in lncRNA expression toward an oncogenic profile, when VDR is deleted. No doubt other pathways will emerge that contribute to a greater or lesser degree to the predisposition of the epidermis lacking VDR and/or Casr to tumor formation.

\section{AUTHOR CONTRIBUTIONS}

DB is the senior author of the paper. He wrote the text and ran the laboratory where the work was done. YJ performed the experiments showing the development of SCC in mice lacking

\section{REFERENCES}

Agar, N. S., Halliday, G. M., Barnetson, R. S., Ananthaswamy, H. N., Wheeler, M., and Jones, A. M. (2004). The basal layer in human squamous tumors harbors more UVA than UVB fingerprint mutations: a role for UVA in human skin carcinogenesis. Proc. Natl. Acad. Sci. U.S.A. 101, 4954-4959. doi: 10.1073/pnas.0401141101

Arimura, S., Matsunaga, A., Kitamura, T., Aoki, K., Aoki, M., and Taketo, M. M. (2009). Reduced level of smoothened suppresses intestinal tumorigenesis by down-regulation of Wnt signaling. Gastroenterology 137, 629-638. doi: 10.1053/j.gastro.2009.04.059

Armstrong, B. K., and Kricker, A. (2001). The epidemiology of UV induced skin cancer. J. Photochem. Photobiol. B 63, 8-18. doi: 10.1016/S1011-1344(01) 00198-1

Aszterbaum, M., Epstein, J., Oro, A., Douglas, V., LeBoit, P. E., Scott, M. P., et al. (1999). Ultraviolet and ionizing radiation enhance the growth of BCCs and trichoblastomas in patched heterozygous knockout mice. Nat. Med. 5, 1285-1291. doi: 10.1038/15242

Aszterbaum, M., Rothman, A., Johnson, R. L., Fisher, M., Xie, J., Bonifas, J. M., et al. (1998). Identification of mutations in the human PATCHED gene in sporadic basal cell carcinomas and in patients with the basal cell nevus syndrome. J. Invest. Dermatol. 110, 885-888. doi: 10.1046/j.1523-1747.1998.00222.x

Barnfield, P. C., Zhang, X., Thanabalasingham, V., Yoshida, M., and Hui, C. C. (2005). Negative regulation of Gli1 and Gli2 activator function by Suppressor of fused through multiple mechanisms. Differentiation 73, 397-405. doi: $10.1111 /$ j.1432-0436.2005.00042.x

Batista, P. J., and Chang, H. Y. (2013). Long noncoding RNAs: cellular address codes in development and disease. Cell 152, 1298-1307. doi: 10.1016/j.cell.2013.02.012

Besaratinia, A., Synold, T. W., Chen, H. H., Chang, C., Xi, B., Riggs, A. D., et al. (2005). DNA lesions induced by UV A1 and B radiation in human cells: comparative analyses in the overall genome and in the p53 tumor suppressor gene. Proc. Natl. Acad. Sci. U.S.A. 102, 10058-10063. doi: $10.1073 /$ pnas. 0502311102

Bhagavathula, N., Hanosh, A. W., Nerusu, K. C., Appelman, H., Chakrabarty, S., and Varani, J. (2007). Regulation of E-cadherin and beta-catenin by Ca2+ in colon carcinoma is dependent on calcium-sensing receptor expression and function. Int. J. Cancer 121, 1455-1462. doi: 10.1002/ijc.22858

Bienz, M. (2005). beta-Catenin: a pivot between cell adhesion and Wnt signalling. Curr. Biol. 15, R64-R67. doi: 10.1016/j.cub.2004.12.058

Bijlsma, M. F., Spek, C. A., Zivkovic, D., van de Water, S., Rezaee, F., and Peppelenbosch, M. P. (2006). Repression of smoothened by patcheddependent (pro-)vitamin D3 secretion. PLoS Biol. 4:e232. doi: 10.1371/ journal.pbio.0040232

Bikle, D. D. (2011). The vitamin D receptor: a tumor suppressor in skin. Discov. Med. 11, 7-17. doi: 10.1139/cjpp-2014-0367

Bikle, D. D. (2012a). Protective actions of vitamin D in UVB induced skin cancer. Photochem. Photobiol. Sci. 11, 1808-1816. doi: 10.1039/c2pp25251a

Bikle, D. D. (2012b). Vitamin, D., and the skin: physiology and pathophysiology. Rev. Endocr. Metab. Disord. 13, 3-19. doi: 10.1007/s11154-011-9194-0

Bikle, D. D., Nemanic, M. K., Gee, E., and Elias, P. (1986). 1,25Dihydroxyvitamin D3 production by human keratinocytes. Kinetics both the VDR and CaSR, as well as the LncRNA profiling. TN assisted with many of the technical aspects of the experiments described in recent publications. YO provided much of the data for the publications involving VDRKO mice. CT developed the CaSRKO mouse and did most of the studies with this mouse.

\section{ACKNOWLEDGMENTS}

This work was supported by grants from the NIH, RO1 AR050023 and AR051930, the Department of Defense CA110338, and the VA IBX001066.

and regulation. J. Clin. Invest. 78, 557-566. doi: 10.1172/JCI 112609

Bikle, D. D., Oda, Y., Tu, C. L., and Jiang, Y. (2015). Novel mechanisms for the vitamin D receptor (VDR) in the skin and in skin cancer. J. Steroid Biochem. Mol. Biol. 148, 47-51. doi: 10.1016/j.jsbmb.2014.10.017

Bikle, D. D., Pillai, S., Gee, E., and Hincenbergs, M. (1991). Tumor necrosis factor-alpha regulation of 1,25-dihydroxyvitamin $\mathrm{D}$ production by human keratinocytes. Endocrinology 129, 33-38. doi: 10.1210/endo-129-1-33

Bonifas, J. M., Pennypacker, S., Chuang, P. T., McMahon, A. P., Williams, M., Rosenthal, A., et al. (2001). Activation of expression of hedgehog target genes in basal cell carcinomas. J. Invest. Dermatol. 116, 739-742. doi: 10.1046/j.15231747.2001.01315.x

Byers, S. W., Rowlands, T., Beildeck, M., and Bong, Y. S. (2011). Mechanism of action of vitamin $\mathrm{D}$ and the vitamin $\mathrm{D}$ receptor in colorectal cancer prevention and treatment. Rev. Endocr. Metab. Disord. 13, 31-38. doi: 10.1007/s11154-0119196-y

Canaff, L., and Hendy, G. N. (2002). Human calcium-sensing receptor gene. Vitamin D response elements in promoters $\mathrm{P} 1$ and P2 confer transcriptional responsiveness to 1,25-dihydroxyvitamin D. J. Biol. Chem. 277, 30337-30350. doi: $10.1074 /$ jbc.M201804200

Chakrabarty, S., Radjendirane, V., Appelman, H., and Varani, J. (2003). Extracellular calcium and calcium sensing receptor function in human colon carcinomas: promotion of E-cadherin expression and suppression of betacatenin/TCF activation. Cancer Res. 63, 67-71.

Chakrabarty, S., Wang, H., Canaff, L., Hendy, G. N., Appelman, H., and Varani, J. (2005). Calcium sensing receptor in human colon carcinoma: interaction with $\mathrm{Ca}(2+)$ and 1,25-dihydroxyvitamin $\mathrm{D}(3)$. Cancer Res. 65, 493-498.

Chan, E. F., Gat, U., McNiff, J. M., and Fuchs, E. (1999). A common human skin tumour is caused by activating mutations in beta-catenin. Nat. Genet. 21, 410-413. doi: 10.1038/7747

Chang, W., Tu, C., Chen, T. H., Bikle, D., and Shoback, D. (2008). The extracellular calcium-sensing receptor (CaSR) is a critical modulator of skeletal development. Sci. Signal. 1:ral. doi: 10.1126/scisignal.1159945

Colston, K., Colston, M. J., and Feldman, D. (1981). 1,25-dihydroxyvitamin D3 and malignant melanoma: the presence of receptors and inhibition of cell growth in culture. Endocrinology 108, 1083-1086. doi: 10.1210/endo-108-3-1083

Colston, K., Colston, M. J., Fieldsteel, A. H., and Feldman, D. (1982). 1,25dihydroxyvitamin D3 receptors in human epithelial cancer cell lines. Cancer Res. 42, 856-859.

D'Orazio, J., Jarrett, S., Amaro-Ortiz, A., and Scott, T. (2013). UV radiation and the skin. Int. J. Mol. Sci. 14, 12222-12248. doi: 10.3390/ijms1406 12222

Ellison, T. I., Smith, M. K., Gilliam, A. C., and Macdonald, P. N. (2008). Inactivation of the vitamin $\mathrm{D}$ receptor enhances susceptibility of murine skin to UV-induced tumorigenesis. J. Invest. Dermatol. 128, 2508-2517. doi: 10.1038/jid.2008.131

English, D. R., Armstrong, B. K., Kricker, A., Winter, M. G., Heenan, P. J., and Randell, P. L. (1998). Case-control study of sun exposure and squamous cell carcinoma of the skin. Int. J. Cancer 77, 347-353.

Fan, H., Oro, A. E., Scott, M. P., and Khavari, P. A. (1997). Induction of basal cell carcinoma features in transgenic human skin expressing Sonic Hedgehog. Nat. Med. 3, 788-792. doi: 10.1038/nm0797-788 
Freeman, S. E., Hacham, H., Gange, R. W., Maytum, D. J., Sutherland, J. C., and Sutherland, B. M. (1989). Wavelength dependence of pyrimidine dimer formation in DNA of human skin irradiated in situ with ultraviolet light. Proc. Natl. Acad. Sci. U.S.A. 86, 5605-5609. doi: 10.1073/pnas.86.14.5605

Garland, C., Shekelle, R. B., Barrett-Connor, E., Criqui, M. H., Rossof, A. H., and Paul, O. (1985). Dietary vitamin D and calcium and risk of colorectal cancer: a 19-year prospective study in men. Lancet 1, 307-309. doi: 10.1016/S01406736(85)91082-7

Gat, U., DasGupta, R., Degenstein, L., and Fuchs, E. (1998). De novo hair follicle morphogenesis and hair tumors in mice expressing a truncated beta-catenin in skin. Cell 95, 605-614. doi: 10.1016/S0092-8674(00)81631-1

Ghahhari, N. M., and Babashah, S. (2015). Interplay between microRNAs and WNT/beta-catenin signalling pathway regulates epithelial-mesenchymal transition in cancer. Eur. J. Cancer 51, 1638-1649. doi: 10.1016/ j.ejca.2015.04.021

Gibb, E. A., Vucic, E. A., Enfield, K. S., Stewart, G. L., Lonergan, K. M., Kennett, J. Y., et al. (2011). Human cancer long non-coding RNA transcriptomes. PLoS ONE 6:e25915. doi: 10.1371/journal.pone.0025915

Gordon-Thomson, C., Gupta, R., Tongkao-on, W., Ryan, A., Halliday, G. M., and Mason, R. S. (2012). 1alpha,25 dihydroxyvitamin D3 enhances cellular defences against UV-induced oxidative and other forms of DNA damage in skin. Photochem. Photobiol. Sci. 11, 1837-1847. doi: 10.1039/c2pp25202c

Grachtchouk, M., Mo, R., Yu, S., Zhang, X., Sasaki, H., Hui, C. C., et al. (2000). Basal cell carcinomas in mice overexpressing Gli2 in skin. Nat. Genet. 24, 216-217. doi: 10.1038/73417

Gutschner, T., and Diederichs, S. (2012). The hallmarks of cancer: a long noncoding RNA point of view. RNA Biol. 9, 703-719. doi: 10.4161/rna.20481

Hahn, H., Wicking, C., Zaphiropoulous, P. G., Gailani, M. R., Shanley, S., Chidambaram, A., et al. (1996). Mutations of the human homolog of Drosophila patched in the nevoid basal cell carcinoma syndrome. Cell 85, 841-851. doi: 10.1016/S0092-8674(00)81268-4

Hohl, D. (1990). Cornified cell envelope. Dermatologica 180, 201-211. doi: $10.1159 / 000248031$

Huelsken, J., Vogel, R., Erdmann, B., Cotsarelis, G., and Birchmeier, W. (2001). beta-Catenin controls hair follicle morphogenesis and stem cell differentiation in the skin. Cell 105, 533-545. doi: 10.1016/S0092-8674(01)00336-1

Hussein, M. R. (2005). Ultraviolet radiation and skin cancer: molecular mechanisms. J. Cutan. Pathol. 32, 191-205. doi: 10.1111/j.03036987.2005.00281.x

Indra, A. K., Castaneda, E., Antal, M. C., Jiang, M., Messaddeq, N., Meng, X., et al. (2007). Malignant transformation of DMBA/TPA-induced papillomas and nevi in the skin of mice selectively lacking retinoid-X-receptor alpha in epidermal keratinocytes. J. Invest. Dermatol. 127, 1250-1260. doi: 10.1038/sj.jid.5700672

Jiang, Y. J., and Bikle, D. D. (2014). LncRNA profiling reveals new mechanism for VDR protection against skin cancer formation. J. Steroid Biochem. Mol. Biol. 144(Pt A), 87-90. doi: 10.1016/j.jsbmb.2013.11.018

$\mathrm{Li}, \mathrm{X}$., Wu, Z., Fu, X., and Han, W. (2013). Long noncoding RNAs: insights from biological features and functions to diseases. Med. Res. Rev. 33, 517-553. doi: 10.1002/med.21254

Lisse, T. S., Saini, V., Zhao, H., Luderer, H. F., Gori, F., and Demay, M. B. (2014). The Vitamin D receptor is required for activation of cWnt and hedgehog signaling in keratinocytes. Mol. Endocrinol. 28, 1698-1706. doi: 10.1210/me.2014-1043

Liu, G., Hu, X., and Chakrabarty, S. (2010). Vitamin D mediates its action in human colon carcinoma cells in a calcium-sensing receptor-dependent manner: downregulates malignant cell behavior and the expression of thymidylate synthase and survivin and promotes cellular sensitivity to 5-FU. Int. J. Cancer 126, 631-639. doi: 10.1002/ijc. 24762

Luderer, H. F., Gori, F., and Demay, M. B. (2011). Lymphoid enhancer-binding factor-1 (LEF1) interacts with the DNA-binding domain of the vitamin D receptor. J. Biol. Chem. 286, 18444-18451. doi: 10.1074/jbc.M110.188219

MacLaughlin, J. A., Anderson, R. R., and Holick, M. F. (1982). Spectral character of sunlight modulates photosynthesis of previtamin D3 and its photoisomers in human skin. Science 216, 1001-1003. doi: 10.1126/science.6281884

Matsumoto, K., Hashimoto, K., Nishida, Y., Hashiro, M., and Yoshikawa, K. (1990). Growth-inhibitory effects of 1,25-dihydroxyvitamin D3 on normal human keratinocytes cultured in serum-free medium. Biochem. Biophys. Res. Commun. 166, 916-923. doi: 10.1016/0006-291X(90)90898-W
Matsuoka, L. Y., Wortsman, J., Haddad, J. G., and Hollis, B. W. (1989). In vivo threshold for cutaneous synthesis of vitamin D3. J. Lab. Clin. Med. 114, 301-305.

Mattick, J. S. (2011). Long noncoding RNAs in cell and developmental biology. Semin. Cell Dev. Biol. 22, 327. doi: 10.1016/j.semcdb.2011.05.002

Mercer, T. R., Dinger, M. E., and Mattick, J. S. (2009). Long non-coding RNAs, insights into functions. Nat. Rev. Genet. 10, 155-159. doi: 10.1038/nrg2521

Mimeault, M., and Batra, S. K. (2010). Frequent deregulations in the hedgehog signaling network and cross-talks with the epidermal growth factor receptor pathway involved in cancer progression and targeted therapies. Pharmacol. Rev. 62, 497-524. doi: 10.1124/pr.109.002329

Muthusamy, V., and Piva, T. J. (2009). The UV response of the skin: a review of the MAPK, NFkappaB and TNFalpha signal transduction pathways. Arch. Dermatol. Res. 302, 5-17. doi: 10.1007/s00403-009-0994-y

Nilsson, M., Undèn, A. B., Krause, D., Malmqwist, U., Raza, K., Zaphiropoulos, P. G., et al. (2000). Induction of basal cell carcinomas and trichoepitheliomas in mice overexpressing GLI-1. Proc. Natl. Acad. Sci. U.S.A. 97, 3438-3443. doi: 10.1073/pnas.97.7.3438

Oda, Y., Tu, C. L., Pillai, S., and Bikle, D. D. (1998). The calcium sensing receptor and its alternatively spliced form in keratinocyte differentiation. J. Biol. Chem. 273, 23344-23352. doi: 10.1074/jbc.273.36.23344

Oda, Y., Uchida, Y., Moradian, S., Crumrine, D., Elias, P., and Bikle, D. (2009). Vitamin D receptor and coactivators SRC 2 and 3 regulate epidermisspecific sphingolipid production and permeability barrier formation. J. Invest. Dermatol. 129, 1367-1378. doi: 10.1038/jid.2008.380

Oro, A. E., Higgins, K. M., Hu, Z., Bonifas, J. M., Epstein, E. H. Jr., and Scott, M. P. (1997). Basal cell carcinomas in mice overexpressing sonic hedgehog. Science 276, 817-821. doi: 10.1126/science.276.5313.817

Pálmer, H. G., Anjos-Afonso, F., Carmeliet, G., Takeda, H., and Watt, F. M. (2008). The vitamin D receptor is a Wnt effector that controls hair follicle differentiation and specifies tumor type in adult epidermis. PLOS ONE 3:e1483. doi: 10.1371/journal.pone.0001483

Pendás-Franco, N., Aguilera, O., Pereira, F., González-Sancho, J. M., and Munoz, A. (2008). Vitamin, D., and Wnt/beta-catenin pathway in colon cancer: role and regulation of DICKKOPF genes. Anticancer Res. 28, 2613-2623.

Pillai, S., Bikle, D. D., and Elias, P. M. (1988). 1,25-Dihydroxyvitamin D production and receptor binding in human keratinocytes varies with differentiation. J. Biol. Chem. 263, 5390-5395.

Ping, X. L., Ratner, D., Zhang, H., Wu, X. L., Zhang, M. J., Chen, F. F., et al. (2001). PTCH mutations in squamous cell carcinoma of the skin. J. Invest. Dermatol. 116, 614-616. doi: 10.1046/j.1523-1747.2001.01301.x

Ratnam, A. V., Bikle, D. D., and Cho, J. K. (1999). 1,25 dihydroxyvitamin D3 enhances the calcium response of keratinocytes. J. Cell. Physiol. 178, 188-196.

Reddy, S. T., Andl, T., Lu, M. M., Morrisey, E. E., and Millar, S. E. (2004). Expression of Frizzled genes in developing and postnatal hair follicles. J. Invest. Dermatol. 123, 275-282. doi: 10.1111/j.0022-202X.2004.23215.x

Regl, G., Kasper, M., Schnidar, H., Eichberger, T., Neill, G. W., Ikram, M. S., et al. (2004a). The zinc-finger transcription factor GLI2 antagonizes contact inhibition and differentiation of human epidermal cells. Oncogene 23, 1263-1274. doi: 10.1038/sj.onc. 1207240

Regl, G., Kasper, M., Schnidar, H., Eichberger, T., Neill, G. W., Philpott, M. P., et al. (2004b). Activation of the BCL2 promoter in response to Hedgehog/GLI signal transduction is predominantly mediated by GLI2. Cancer Res. 64, 7724-7731. doi: 10.1158/0008-5472.CAN-04-1085

Regl, G., Neill, G. W., Eichberger, T., Kasper, M., Ikram, M. S., Koller, J., et al. (2002). Human GLI2 and GLI1 are part of a positive feedback mechanism in Basal Cell Carcinoma. Oncogene 21, 5529-5539. doi: 10.1038/sj.onc.12 05748

Rey, O., Chang, W., Bikle, D., Rozengurt, N., Young, S. H., and Rozengurt, E. (2011). Negative cross-talk between calcium-sensing receptor and beta-catenin signaling systems in colonic epithelium. J. Biol. Chem. 287, 1158-1167. doi: 10.1074/jbc.M111.274589

Rosso, S., Zanetti, R., Martinez, C., Tormo, M. J., Schraub, S., Sancho-Garnier, H., et al. (1996). The multicentre south European study 'Helios'. II: different sun exposure patterns in the aetiology of basal cell and squamous cell carcinomas of the skin. Br. J. Cancer 73, 1447-1454. doi: 10.1038/bjc.1996.275

Schauber, J., Dorschner, R. A., Coda, A. B., Büchau, A. S., Liu, P. T., Kiken, D., et al. (2007). Injury enhances TLR2 function and antimicrobial peptide expression 
through a vitamin D-dependent mechanism. J. Clin. Invest. 117, 803-811. doi: 10.1172/JCI30142

Schneider, F. T., Schänzer, A., Czupalla, C. J., Thom, S., Engels, K., Schmidt, M. $\mathrm{H}$., et al. (2010). Sonic hedgehog acts as a negative regulator of \{beta\}-catenin signaling in the adult tongue epithelium. Am. J. Pathol. 177, 404-414. doi: 10.2353/ajpath.2010.091079

Sekulic, A., Migden, M. R., Oro, A. E., Dirix, L., Lewis, K. D., Hainsworth, J. D., et al. (2012). Efficacy and safety of vismodegib in advanced basal-cell carcinoma. N. Engl. J. Med. 366, 2171-2179. doi: 10.1056/NEJMoa1113713

Spitale, R. C., Crisalli, P., Flynn, R. A., Torre, E. A., Kool, E. T., and Chang, H. Y. (2013). RNA SHAPE analysis in living cells. Nat. Chem. Biol. 9, 18-20. doi: $10.1038 /$ nchembio. 1131

Su, M. J., Bikle, D. D., Mancianti, M. L., and Pillai, S. (1994). 1,25Dihydroxyvitamin D3 potentiates the keratinocyte response to calcium. J. Biol. Chem. 269, 14723-14729.

Svärd, J., Heby-Henricson, K., Persson-Lek, M., Rozell, B., Lauth, M., Bergstrom, A., et al. (2006). Genetic elimination of Suppressor of fused reveals an essential repressor function in the mammalian Hedgehog signaling pathway. Dev. Cell 10, 187-197. doi: 10.1016/j.devcel.2005.12.013

Tang, J. Y., Mackay-Wiggan, J. M., Aszterbaum, M., Yauch, R. L., Lindgren, J., Chang, K., et al. (2012). Inhibiting the hedgehog pathway in patients with the basal-cell nevus syndrome. N. Engl. J. Med. 366, 2180-2188. doi: 10.1056/NEJMoa1113538

Tang, J. Y., Xiao, T. Z., Oda, Y., Chang, K. S., Shpall, E., Wu, A., et al. (2011). Vitamin D3 inhibits hedgehog signaling and proliferation in murine Basal cell carcinomas. Cancer Prev. Res. (Phila) 4, 744-751. doi: 10.1158/19406207.CAPR-10-0285

Teichert, A., Elalieh, H., and Bikle, D. (2010). Disruption of the hedgehog signaling pathway contributes to the hair follicle cycling deficiency in Vdr knockout mice. J. Cell. Physiol. 225, 482-489. doi: 10.1002/jcp.22227

Teichert, A., Elalieh, H., Elias, P., Welsh, J., and Bikle, D. (2011). Overexpression of hedgehog signaling is associated with epidermal tumor formation in vitamin D receptor null mice. J. Invest. Dermatol. 131, 2289-2297. doi: $10.1038 /$ jid.2011.196

Teichert, A. E., Elalieh, H., Elias, P. M., Welsh, J., and Bikle, D. D. (2011). Overexpression of hedgehog signaling is associated with epidermal tumor formation in vitamin D receptor-null mice. J. Invest. Dermatol. 131, 2289-2297. doi: 10.1038/jid.2011.196

Thacher, S. M., and Rice, R. H. (1985). Keratinocyte-specific transglutaminase of cultured human epidermal cells: relation to cross-linked envelope formation and terminal differentiation. Cell 40, 685-695. doi: 10.1016/00928674(85)90217-X

Tojo, M., Mori, T., Kiyosawa, H., Honma, Y., Tanno, Y., Kanazawa, K. Y., et al. (1999). Expression of sonic hedgehog signal transducers, patched and smoothened, in human basal cell carcinoma. Pathol. Int. 49, 687-694. doi: 10.1046/j.1440-1827.1999.00938.x

Tu, C., Chang, W., Xie, Z., and Bikle, D. D. (2008). Inactivation of the calcium sensing receptor inhibits E-cadherin-mediated cell-cell adhesion and calciuminduced differentiation in human epidermal keratinocytes. J. Biol. Chem. 283, 3519-3528. doi: 10.1074/jbc.M708318200

Tu, C. L., Chang, W., and Bikle, D. D. (2001). The extracellular calciumsensing receptor Is Required for calcium- induced differentiation in human keratinocytes. J. Biol. Chem. 276, 41079-41085. doi: 10.1074/jbc.M107122200

Tu, C. L., Chang, W., and Bikle, D. D. (2005). Phospholipase cgamma1 is required for activation of store-operated channels in human keratinocytes. J. Invest. Dermatol. 124, 187-197. doi: 10.1111/j.0022-202X.2004.23544.x

Tu, C. L., Chang, W., and Bikle, D. D. (2007). The role of the calcium sensing receptor in regulating intracellular calcium handling in human epidermal keratinocytes. J. Invest. Dermatol. 127, 1074-1083. doi: 10.1038/sj.jid.57 00633

Tu, C. L., Chang, W., and Bikle, D. D. (2011). The calcium-sensing receptordependent regulation of cell-cell adhesion and keratinocyte differentiation requires Rho and filamin A. J. Invest. Dermatol. 131, 1119-1128. doi: 10.1038/jid.2010.414

Tu, C. L., Chang, W., Xie, Z., and Bikle, D. D. (2008). Inactivation of the calcium sensing receptor inhibits E-cadherin-mediated cell-cell adhesion and calciuminduced differentiation in human epidermal keratinocytes. J. Biol. Chem. 283, 3519-3528. doi: 10.1074/jbc.M708318200
Tu, C. L., Crumrine, D. A., Man, M. Q., Chang, W., Elalieh, H., You, M., et al. (2012). Ablation of the calcium-sensing receptor in keratinocytes impairs epidermal differentiation and barrier function. J. Invest. Dermatol. 132, 2350-2359. doi: 10.1038/jid.2012.159

Tu, C. L., Oda, Y., Komuves, L., and Bikle, D. D. (2004). The role of the calciumsensing receptor in epidermal differentiation. Cell Calcium 35, 265-273. doi: 10.1016/j.ceca.2003.10.019

Varnat, F., Duquet, A., Malerba, M., Zbinden, M., Mas, C., Gervaz, P., et al. (2009). Human colon cancer epithelial cells harbour active HEDGEHOGGLI signalling that is essential for tumour growth, recurrence, metastasis and stem cell survival and expansion. EMBO Mol. Med. 1, 338-351. doi: 10.1002/emmm.200900039

Wang, T. T., Tavera-Mendoza, L. E., Laperriere, D., Libby, E., MacLeod, N. B., Nagai, Y., et al. (2005). Large-scale in silico and microarray-based identification of direct 1,25-dihydroxyvitamin D3 target genes. Mol. Endocrinol. 19, 2685-2695. doi: 10.1210/me.2005-0106

Wang, X., Chen, W., Singh, N., Promkan, M., and Liu, G. (2010). Effects of potential calcium sensing receptor inducers on promoting chemosensitivity of human colon carcinoma cells. Int. J. Oncol. 36, 1573-1580.

Wei, G., Ku, S., Ma, G. K., Saito, S., Tang, A. A., Zhang, J., et al. (2007). HIPK2 represses beta-catenin-mediated transcription, epidermal stem cell expansion, and skin tumorigenesis. Proc. Natl. Acad. Sci. U.S.A. 104, 13040-13045. doi: 10.1073/pnas.0703213104

Xia, J., Urabe, K., Moroi, Y., Koga, T., Duan, H., Li, Y., et al. (2006). beta-Catenin mutation and its nuclear localization are confirmed to be frequent causes of Wnt signaling pathway activation in pilomatricomas. J. Dermatol. Sci. 41, 67-75. doi: 10.1016/j.jdermsci.2005.09.005

Xie, Z., and Bikle, D. D. (1997). Cloning of the human phospholipase C-gamma1 promoter and identification of a DR6-type vitamin D-responsive element. J. Biol. Chem. 272, 6573-6577. doi: 10.1074/jbc.272.10.6573

Xie, Z., and Bikle, D. D. (2007). The recruitment of phosphatidylinositol 3-kinase to the E-cadherin-catenin complex at the plasma membrane is required for calcium-induced phospholipase C-gammal activation and human keratinocyte differentiation. J. Biol. Chem. 282, 8695-8703. doi: 10.1074/jbc.M609135200

Xie, Z., Chang, S. M., Pennypacker, S. D., Liao, E. Y., and Bikle, D. D. (2009). Phosphatidylinositol-4-phosphate 5-kinase lalpha mediates extracellular calcium-induced keratinocyte differentiation. Mol. Biol. Cell 20, 1695-1704. doi: 10.1091/mbc.E08-07-0756

Xie, Z., Singleton, P. A., Bourguignon, L. Y., and Bikle, D. D. (2005). Calcium-induced human keratinocyte differentiation requires src- and fynmediated phosphatidylinositol 3-kinase-dependent activation of phospholipase C-gamma1. Mol. Biol. Cell 16, 3236-3246. doi: 10.1091/mbc.E05-02-0109

Yang, S. H., Andl, T., Grachtchouk, V., Wang, A., Liu, J., Syu, L. J., et al. (2008). Pathological responses to oncogenic Hedgehog signaling in skin are dependent on canonical Wnt/beta3-catenin signaling. Nat. Genet. 40, 1130-1135. doi: 10.1038/ng.192

Youssef, K. K., Lapouge, G., Bouvrée, K., Rorive, S., Brohée, S., Appelstein, O., et al. (2012). Adult interfollicular tumour-initiating cells are reprogrammed into an embryonic hair follicle progenitor-like fate during basal cell carcinoma initiation. Nat. Cell Biol. 14, 1282-1294. doi: 10.1038/ncb2628

Yuspa, S. H., Kilkenny, A. E., Steinert, P. M., and Roop, D. R. (1989). Expression of murine epidermal differentiation markers is tightly regulated by restricted extracellular calcium concentrations in vitro. J. Cell Biol. 109, 1207-1217. doi: 10.1083/jcb.109.3.1207

Zinser, G. M., Sundberg, J. P., and Welsh, J. (2002). Vitamin D(3) receptor ablation sensitizes skin to chemically induced tumorigenesis. Carcinogenesis 23 , 2103-2109. doi: 10.1093/carcin/23.12.2103

Conflict of Interest Statement: The authors declare that the research was conducted in the absence of any commercial or financial relationships that could be construed as a potential conflict of interest.

Copyright $\odot 2016$ Bikle, Jiang, Nguyen, Oda and Tu. This is an open-access article distributed under the terms of the Creative Commons Attribution License (CC BY). The use, distribution or reproduction in other forums is permitted, provided the original author(s) or licensor are credited and that the original publication in this journal is cited, in accordance with accepted academic practice. No use, distribution or reproduction is permitted which does not comply with these terms. 